Check for updates

Cite this: RSC Adv., 2019, 9, 15307

\title{
A photoelectrochemical glucose sensor based on gold nanoparticles as a mimic enzyme of glucose oxidase $\uparrow$
}

\author{
Ling Cao, Panpan Wang, Li Chen, Ying Wu and Junwei Di (D)*
}

\begin{abstract}
This work reports the first construction of the ternary layers of $1 \mathrm{TO} / \mathrm{PbS} / \mathrm{SiO}_{2} / \mathrm{AuNPs}$ nanostructure for development of photoelectrochemical (PEC) glucose sensor. Herein, the thioglycolic acid-capped PbS quantum dots was employed as a PEC active probe, which is very sensitive to oxygen. The small gold nanoparticles (AuNPs) were act as nanozyme (mimic enzyme of glucose oxidase) to catalytically oxidize glucose in the presence of oxygen, meanwhile consumed oxygen and then resulted in the decrease of cathodic photocurrent. The insertion layer of $\mathrm{SiO}_{2}$ nanoparticles between $\mathrm{PbS}$ and AuNPs could reduce efficiently the base current due to its low electroconductivity, which improved the detection limit. The proposed PEC sensor exhibited high sensitivity and gold selectivity towards glucose. The linear response of glucose concentrations ranged from $1.0 \mu \mathrm{M}$ to $1.0 \mathrm{mM}$ with detection limit of $0.46 \mu \mathrm{M}(\mathrm{S} / \mathrm{N}=3)$. The results suggest the potential of design and development of numerous nanozyme-based PEC biosensors with the advantage of the simplicity, stability, and efficiency.
\end{abstract}

Received 18th March 2019 Accepted 5th May 2019

DOI: 10.1039/c9ra02088h

rsc.li/rsc-advances glucose detection method..$^{25}$ However, the disadvantages, such as the degeneration and digestion of enzymes, the sensitivity of catalytic activity to environmental conditions, the difficulty in recovery and the high cost, have greatly restricted the application of natural enzyme. ${ }^{23}$

Recently, enzyme-mimetic nanomaterials (nanozymes) have been attracted greatly due to their simple preparation, low cost, and high stability. ${ }^{26}$ Because of the characteristics of simple preparation, good biocompatibility and unique photoelectron performance, gold nanoparticles (AuNPs) have attracted more and more attention in many fields. ${ }^{27}$ Moreover, small AuNPs were demonstrated to have catalytic properties similar to GOD. ${ }^{28,29}$ In the presence of oxygen, they can catalytically oxidize glucose to produce gluconic acid and hydrogen peroxide. This catalytic reaction has been employed to detect glucose in colorimetry. ${ }^{30,31}$

Herein, a new PEC sensor was constructed for detection of glucose. The PEC biosensor was prepared with multi-layer $\mathrm{PbS}$ quantum dots (PbS QDs) on the indium tin oxide (ITO) electrode surface, which led efficient photocurrent response. Small AuNPs was used as mimic enzyme of GOD, catalyzing the glucose oxidation to gluconic acid with consuming oxygen in situ. The insulated $\mathrm{SiO}_{2}$ nanospheres $\left(\mathrm{SiO}_{2} \mathrm{NSs}\right)$ were inserted between the layers of $\mathrm{PbS}$ and AuNPs, which could efficiently reduce the base current and improve the detection limit. It is demonstrated that this nanozyme-based biosensor can be successfully used in the PEC detection of glucose, substituting for nature enzyme.
College of Chemistry, Chemical Engineering and Material Science, Soochow University, Suzhou, 215123, PR China.E-mail:20164209007@stu.suda.edu.cn; 985604192@qq. com;1610796834@qq.com; yingwu@suda.edu.cn; djw@suda.edu.cn

$\dagger$ Electronic supplementary information (ESI) available. See DOI: 10.1039/c9ra02088h 


\section{Experimental section}

\section{Reagents and apparatus}

$\mathrm{Pb}\left(\mathrm{NO}_{3}\right)_{2}$, tetraethyl orthosilicate (TEOS), (3-mercaptopropyl)trimethoxysilane, $\mathrm{NH}_{3} \cdot \mathrm{H}_{2} \mathrm{O}$, ethanol, trisodium citrate dehydrate $\left(\mathrm{C}_{6} \mathrm{H}_{5} \mathrm{Na}_{3} \mathrm{O}_{7} \cdot 2 \mathrm{H}_{2} \mathrm{O}\right)$, tetrachloroauric acid $\left(\mathrm{HAuCl}_{4} \cdot 4 \mathrm{H}_{2} \mathrm{O}\right)$, tris-(hydroxymethyl)aminomethane (Tris- $\mathrm{HCl}$ ), sodium hydroxide and D-(+)-glucose were purchased from Sinopharm Chemical Reagent Co., Ltd. (China). Thioglycolic acid (TGA) was purchased from Acros Organics. Poly-(diallyldimethylammonium chloride) (PDDA), $\mathrm{Na}_{2} \mathrm{~S} \cdot 9 \mathrm{H}_{2} \mathrm{O}$, sodium borohydride $\left(\mathrm{NaHB}_{4}\right.$, 98\%)were purchased from Aladdin Chemical Reagent Co. Ltd. ITO thin film coated glass $(1.1 \mathrm{~mm}$, $\sim 100 \Omega \square^{-1}$ ) was purchased from Suzhou SNSG Electronics Co. Ltd. The ITO substrates $(50 \times 10 \mathrm{~mm})$ were cleaned in dilute ammonia water, ethanol and ultrapure water with ultrasonication, followed by drying with $\mathrm{N}_{2}$. All solutions were prepared with ultrapure water $(18.2 \mathrm{M} \Omega \mathrm{cm})$.

Transmission electron microscopy (TEM) image was obtained on a Tecnai G20 transmission electron microscope (FEI, U.S.A). Scanning electron microscopy (SEM) was performed using S-4700 SEM (Hitachi, Japan). The phase structure of the sample was measured by X-ray powder diffraction (XRD) on MiniFlex 300/600 XRD (Japan). X-ray photoelectron spectroscopy (XPS) was obtained from ESCALAB220i-XL. Photocurrent was measured on a RST5200 electrochemical workstation (Suzhou Risetest Electronic Co., Ltd., China). A PbS/SiO $2 / \mathrm{AuNPs}$ (the surface area is $0.25 \mathrm{~cm}^{2}$ ) modified ITO electrode was employed as the working electrode. A Pt wire was used as the counter electrode, and a saturated calomel electrode (SCE) as the reference electrode. A LED lamp with the wavelength of $470 \mathrm{~nm}$ was used as irradiation source (Brillante, Tianjin, China).

\section{Synthesis of TGA-stabilized PbS QDs}

TGA-capped PbS QDs were synthesized in aqueous solution using a slightly modified procedure. ${ }^{32}$ Firstly, $0.16 \mathrm{mmol}$ of lead acetate trihydrate was dissolved in $50 \mathrm{~mL}$ of ultrapure water, and the air in the solution was removed with $\mathrm{N}_{2}$ gas for $30 \mathrm{~min}$. Then $50 \mu \mathrm{L}$ TGA was dropped into the flask under strong magnetic stirring. The $\mathrm{pH}$ value of the solution was adjusted to 11.0 with $1 \mathrm{~mol} \mathrm{~L}^{-1} \mathrm{NaOH}$. Next, the solution of $\mathrm{Na}_{2} \mathrm{~S}(4 \mathrm{~mL}$, $0.015 \mathrm{~mol} \mathrm{~L}^{-1}$ ) without oxygen was slowly injected into the solution. Immediately, the solution turned from colorless to dark-brown. The reaction mixture was stirred under a $\mathrm{N}_{2}$ atmosphere for $3 \mathrm{~h}$. The as-synthesized TGA-capped PbS QDs were stored at $4{ }^{\circ} \mathrm{C}$.

\section{Synthesis of thiol-modified $\mathrm{SiO}_{2}$ NSs}

The utilized $\mathrm{SiO}_{2}$ were synthesized according to the previous report. ${ }^{33}$ By adding $1 \mathrm{~mL}$ TEOS in a mixture of ethanol $(35.7 \mathrm{~mL})$, water $(5 \mathrm{~mL})$ and ammonia $(0.8 \mathrm{~mL}), \mathrm{SiO}_{2} \mathrm{NSs}$ were synthesized. After stirring for $24 \mathrm{~h}$ at $30{ }^{\circ} \mathrm{C}$, the product was rinsed by water and ethanol, and then dissolved in $10 \mathrm{~mL}$ ethanol. The above solution were treated with $50 \mu \mathrm{L}$ (3-mercaptopropyl) trimethoxysilane and stirred for $24 \mathrm{~h}$ at $30{ }^{\circ} \mathrm{C}$ to obtain thiolgroups modified $\mathrm{SiO}_{2} \mathrm{NSs}$.

\section{Synthesis of small AuNPs}

AuNPs were synthesized in aqueous solution according to our previously reported work. ${ }^{34}$ Firstly, $0.5 \mathrm{~mL} \mathrm{HAuCl}_{4}(10 \mathrm{mM})$, $0.5 \mathrm{~mL} \mathrm{C}_{6} \mathrm{H}_{5} \mathrm{Na}_{3} \mathrm{O}_{7} \cdot 2 \mathrm{H}_{2} \mathrm{O}(10 \mathrm{mM})$ aqueous solution and $19 \mathrm{~mL}$ ultrapure water were mixed at room temperature. Then, $0.5 \mathrm{~mL}$ freshly prepared $\mathrm{NaHB}_{4}(0.1 \mathrm{mM})$ was added to the solution under stirring. The solution became orange red immediately. Further stirring about 5-10 $\mathrm{min}$, the gold nanoparticles solution was stable and stored in a refrigerator at $4{ }^{\circ} \mathrm{C}$ for future use.

\section{Fabrication of the ITO/PbS/SiO $/ \mathrm{SuNPs}_{2}$ electrode}

The modification of PbS QDs on ITO electrode was according to previously reported methods based on the electrostatic interaction between positively charged PDDA and negatively charged TGA-capped PbS QDs. The ITO/PbS electrodes $(10 \times 10 \mathrm{~mm})$ were fabricated by being alternately immersed into a solution of $2 \%$ aqueous PDDA containing $0.5 \mathrm{M} \mathrm{NaCl}$ and the TGA-capped $\mathrm{PbS}$ QDs solution for 10 minutes. For each step, the surfaces of electrodes were washed with ultrapure water and dried with nitrogen. The process was repeated by dipping in PDDA and PbS QDs solutions to obtain multilayers of PbS QDs modified electrodes. Next, $50 \mu \mathrm{L}$ thiol-modified $\mathrm{SiO}_{2} \mathrm{NSs}$ were added onto the PbS-modified ITO electrode, and dried naturally. Blowing off the unsound $\mathrm{SiO}_{2} \mathrm{NSs}, 50 \mu \mathrm{L}$ gold nanoparticles solution was dropped onto the ITO $/ \mathrm{PbS} / \mathrm{SiO}_{2}$ electrode and then dried in an oven at $50{ }^{\circ} \mathrm{C}$. The prepared electrode was defined as ITO/PbS/ $\mathrm{SiO}_{2} /$ AuNPs electrode.

\section{Photoelectrochemical detection of glucose}

For glucose detection, the ITO/PbS/SiO $/$ AuNPs electrode was immersed in $10 \mathrm{~mL}$ of $0.1 \mathrm{M}$ Tris-HCl buffer ( $\mathrm{pH} 7.4$ ) with passing into oxygen gas for 5 minutes. The blank photocurrent was recorded. Then $100 \mu \mathrm{L}$ of certain concentration of glucose was added into the solution for the photocurrent measurements at room temperature. The decrease of the photocurrent intensity was employed for quantitative detection of glucose. To detect glucose in real samples, the diluted serum sample (the real samples were obtained from local hospital) was measured by the same procedure.

\section{Results and discussion}

\section{Morphological and structural characterization}

TEM and XRD were utilized to reveal morphological and structural information about the samples. Fig. S1† shows the TEM image of the as-synthesized TGA-capped PbS QDs, thiolmodified $\mathrm{SiO}_{2}$ NSs and small AuNPs, which appeared as quasi-spherical particles with average size of $\sim 5 \mathrm{~nm}, \sim 50 \mathrm{~nm}$, and $\sim 4 \mathrm{~nm}$, respectively. Fig. S2 $\uparrow$ displayed the XRD pattern of the as-fabricated $\mathrm{PbS}$ QDs, thiol-modified $\mathrm{SiO}_{2}$ and gold nanoparticles. The XRD pattern of the PbS QDs exhibits sharp prominent peaks at scattering angles $(2 \theta)$ of $25.89^{\circ}, 30.02^{\circ}$, $43.16^{\circ}, 50.89^{\circ}, 53.21^{\circ}, 62.49^{\circ}, 68.81^{\circ}, 71.96^{\circ}$, and $78.87^{\circ}$, 
indexed to scattering from the (111), (200), (220), (311), (222), (400), (331), (420), and (422) planes, respectively, of the standard cubic PbS (JCPDS card no. 5-592). This pattern indicated that the sample was face-centered cubic PbS. The second pattern indicated that the as-synthesized $\mathrm{SiO}_{2}$ was amorphous structure with characteristic peaks at $2 \theta$ values of $22.9^{\circ}$ (JCPDS card no. 29-0085). The third pattern of the Au would indexed all the observed peaks to the face-centered cubic $\mathrm{Au}$, with characteristic peaks of the Au at $2 \theta$ values of $38.26^{\circ}, 44.67^{\circ}, 64.81^{\circ}$, and $77.53^{\circ}$ corresponding to the (111), (200), (220), and (311) crystal planes, respectively, of cubic Au (JCPDS card no. 04-0784). All of these verified the successful synthesis of PbS QDs, thiolmodified $\mathrm{SiO}_{2}$ and gold nanoparticles.

\section{Characterization of $\mathrm{ITO} / \mathrm{PbS} / \mathrm{SiO}_{2} / \mathrm{AuNPs}$ electrode}

Fig. 1a shows the SEM image of PbS QDs deposited onto the ITO surface. It can be seen that the majority of $\mathrm{PbS}$ particles are uniformly distributed on the ITO glass with a small amount of aggregation. Further assembly of $\mathrm{SiO}_{2}$ NSs on the ITO glass (Fig. 1b), the spheroidal $\mathrm{SiO}_{2}$ particles were coated on the ITO/ $\mathrm{PbS}$ electrode with size of $\sim 50 \mathrm{~nm}$ nanoparticles on the electrode surface, indicating that the $\mathrm{SiO}_{2}$ particles were successfully assembled onto the PbS surface. Finally, the AuNPs were assembled to the surface of electrode (Fig. 1c). It can be seen from the inset figure that some small gold nanoparticles were distributed around the large $\mathrm{SiO}_{2}$ nanoparticles, indicating that AuNPs was successfully immobilized on the electrode surface. In order to further explore the distribution of $\mathrm{PbS}, \mathrm{SiO}_{2}$ and $\mathrm{Au}$ on the ITO surface, a mapping analysis was performed on a region of the SEM image. As shown in Fig. 1d, the elements $\mathrm{Pb}, \mathrm{S}, \mathrm{Si}$, and $\mathrm{Au}$ were uniformly distributed on the surface of the electrode, and it was verified that $\mathrm{PbS}, \mathrm{SiO}_{2}$, and AuNPs were successfully modified onto the ITO glass.

XPS was further performed to study the surface chemical compositions and oxidation states of the ITO/PbS/SiO $/$ /AuNPs electrode. The peak positions were determined with a $\mathrm{C} 1 \mathrm{~s}$
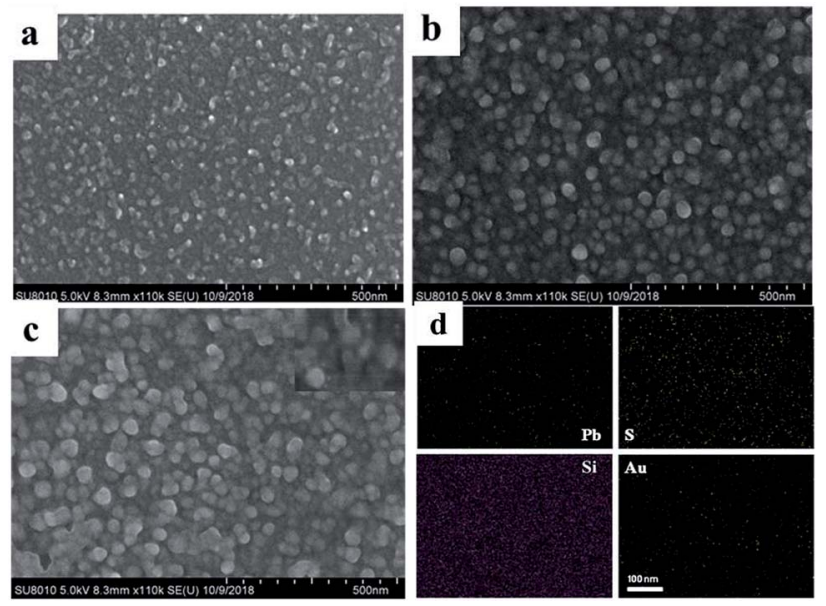

Fig. 1 SEM images of (a) ITO/PbS, (b) ITO/PbS/SiO AuNPs electrodes. (d) Elemental mapping of the ITO/PbS/SiO $2 /$ AuNPs nanofilm. binding energy of $284.6 \mathrm{eV}$ as the internal marked standard. Fig. 2a depicts the full-scan XPS spectrum of the $\mathrm{PbS} / \mathrm{SiO}_{2} /$ AuNPs nanofilm with the relevant elements being $\mathrm{Pb}, \mathrm{S}, \mathrm{Si}, \mathrm{O}$, $\mathrm{Au}$ and $\mathrm{C}$. The corresponding high-resolution XPS spectra of $\mathrm{Pb}$ 4f, S 2p, Si 2p, Au 2p, and O 1s are also illustrated. The peak of C $1 \mathrm{~s}$ in the graph was due to adventitious hydrocarbons from the instrument. Fig. $2 \mathrm{~b}$ presents the $\mathrm{Pb} 4 \mathrm{f}_{7 / 2}$ and $\mathrm{Pb} 4 \mathrm{f}_{5 / 2}$ signal with maxima located at $\sim 138 \mathrm{eV}$ and $\sim 143 \mathrm{eV}$, while Fig. 2c shows the $\mathrm{S} 2 \mathrm{p}$ signal consisted of $\mathrm{S} 2 \mathrm{p}_{1 / 2}$ and $\mathrm{S} 2 \mathrm{p}_{3 / 2}$ at around $163 \mathrm{eV}$, which should be assigned to the PbS compound. Fig. $2 \mathrm{~d}$ of Si $2 \mathrm{p}$ exhibits a peak at around $103 \mathrm{eV}$. Fig. 2e of the $\mathrm{O} 1 \mathrm{~s}$ spectrum exhibits a peak at binding energies of $\sim 532 \mathrm{eV}$. The peaks at $532 \mathrm{eV}$ can be assigned to $\mathrm{O}^{2-}$ in octahedral symmetry (bulk O) associated with $\mathrm{SiO}_{2}$ species. Fig. $2 \mathrm{f}$ presents the $\mathrm{Au} 4 \mathrm{f}_{7 / 2}$ and $\mathrm{Au}$ $4 \mathrm{f}_{5 / 2}$ signal with maxima located at $\sim 83 \mathrm{eV}$ and $\sim 87 \mathrm{eV}$.

It is known that electrochemical impedance spectroscopy (EIS) can provide information on the electron-transfer property of electrode. The assembly process of the electrode can be described by the resistance of the electrode. Fig. 3 shows the EIS of different electrodes using $\mathrm{K}_{3} \mathrm{Fe}(\mathrm{CN})_{6} / \mathrm{K}_{4} \mathrm{Fe}(\mathrm{CN})_{6}$ as an electrochemical probe. When the PbS QDs were assembled on the ITO electrode, the diameter of the semicircle increased due to the semiconductor characteristics of PbS. After $\mathrm{SiO}_{2}$ had further deposited on the $\mathrm{ITO} / \mathrm{PbS}$ electrode, the electron-transfer resistance further increased because the $\mathrm{SiO}_{2}$ insulator blocked the electron-transfer between the electrochemical probe and electrode. When the AuNPs were assembled on the electrode, the diameter of the semicircle decreased due to the
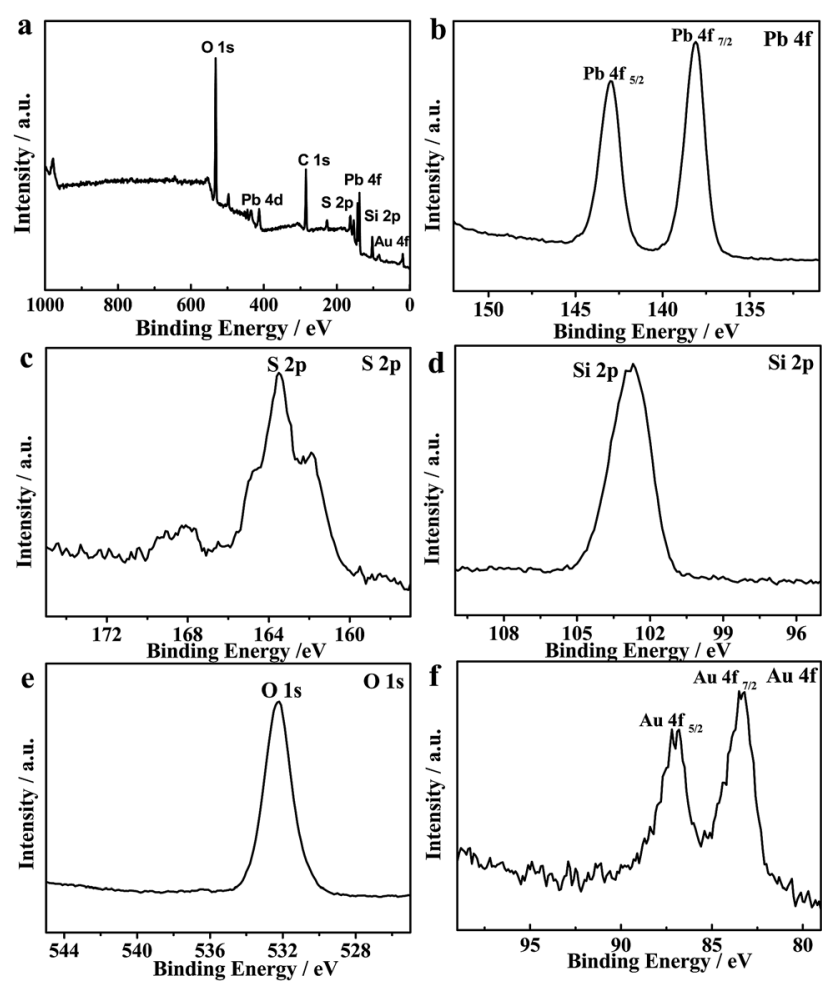

Fig. 2 (a) Full-scan XPS spectrum of the as-fabricated $\mathrm{PbS} / \mathrm{SiO}_{2} /$ AuNPs nanofilm and $(b-f)$ high-resolution XPS spectra of $\mathrm{Pb} 4 \mathrm{f}, \mathrm{S} 2 \mathrm{p}, \mathrm{Si}$ $2 \mathrm{p}, \mathrm{O} 1 \mathrm{~s}$, and $\mathrm{Au} 4 \mathrm{f}$, respectively. 


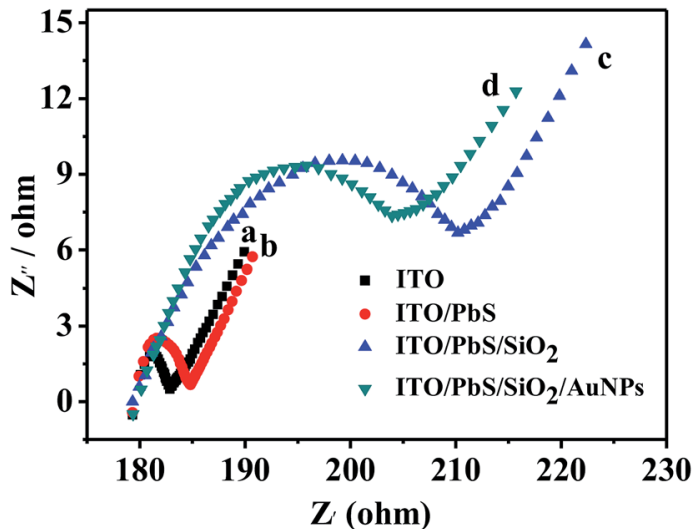

Fig. 3 The EIS of (a) bare ITO, (b) ITO/PbS, (c) ITO/PbS/SiO , and (d) $\mathrm{ITO} / \mathrm{PbS} / \mathrm{SiO}_{2} / \mathrm{AuNPs}$ electrode in $5 \mathrm{mM}\left[\mathrm{Fe}(\mathrm{CN})_{6}\right]^{3-/ 4-}$ solution.

introduction of excellent electrical conductivity of Au. According to the pattern, the resistances of all these electrodes were not particularly big. This implies that the ITO/PbS/SiO $/$ /AuNPs electrode exhibited good electron-transfer property. This further verifies that $\mathrm{SiO}_{2}$ and gold nanoparticles are successfully modified to PbS quantum dots.

\section{Photoelectrochemical sensing mechanism}

Fig. 4 shows the photocurrent of $\mathrm{ITO} / \mathrm{PbS} / \mathrm{SiO}_{2} / \mathrm{AuNPs}$ electrode in $0.1 \mathrm{M}$ Tris-HCl buffer solution $(\mathrm{pH}=7.4)$ with the blue LED light irradiation before and after addition of $1 \mathrm{mM}$ glucose solution. The photocurrent value of the $\mathrm{ITO} / \mathrm{PbS} / \mathrm{SiO}_{2} / \mathrm{AuNPs}$ electrode in $\mathrm{N}_{2}$-saturated solution was about $70 \mathrm{nA}$. While the photocurrent value in the oxygen-containing buffer solution was about $1.2 \mu \mathrm{A}$, which indicated that the oxygen in the solution has a great influence on it. It is well known that $\mathrm{PbS}$ is a ptype semiconductor with holes as the main carrier. When the PbS QDs absorb the matched energy, the electrons are excited from the valence band (VB) to the conduction band (CB). The photoelectron transfer rate to electrolyte solution is faster than

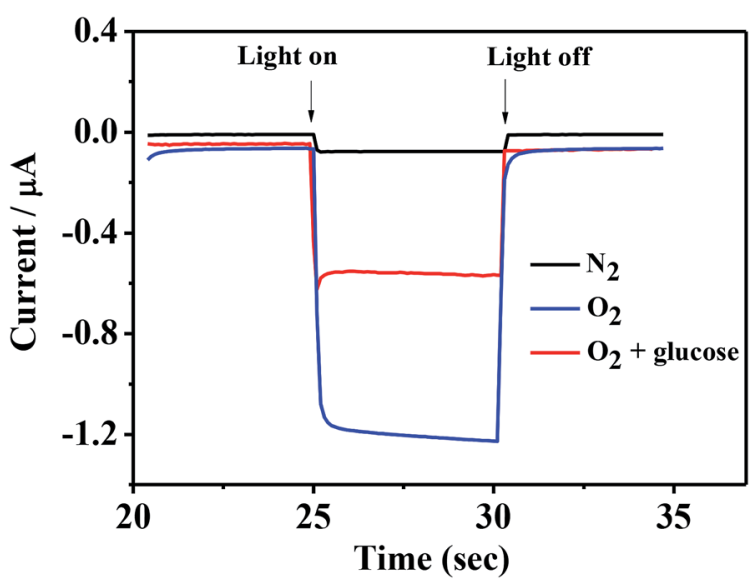

Fig. 4 Photocurrent responses of the ITO/PbS/SiO $/$ AuNPs electrode in a $\mathrm{N}_{2}$ (black), oxygen (red) and after addition of $1 \mathrm{mM}$ glucose at applied potential of $-0.2 \mathrm{~V}$ (vs. SCE) under visible light irradiation.

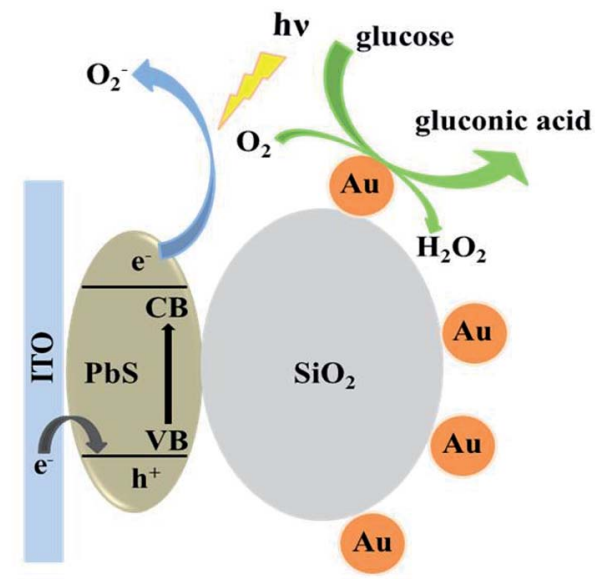

Scheme 1 Schematic illustration of the PEC strategy for detection of glucose at ITO/PbS/SiO $/$ /AuNPs electrode.

that of hole capture through ITO electrode, resulting in cathode photocurrent generation. Thus $\mathrm{PbS}$ is extremely sensitive to oxygen which is act as electron acceptor. ${ }^{35}$ Furthermore, the photocurrent of the ITO/PbS/SiO $/$ AuNPs electrode was significantly reduced to about $0.5 \mu \mathrm{A}$ after addition of $1 \mathrm{mM}$ glucose in the system. The PEC mechanism of glucose response at the ITO/ $\mathrm{PbS} / \mathrm{SiO}_{2} / \mathrm{AuNPs}$ electrode is illustrated in Scheme 1. The AuNPs on the electrode surface act as a GOD mimic enzyme. In the presence of $\mathrm{O}_{2}$, AuNPs catalytically oxidize glucose to produce gluconic acid and hydrogen peroxide. Meanwhile, the oxygen is consumed, which decreases the concentration of the electron acceptor on the electrode surface. Therefore, the intensity of the cathode photocurrent decreased as addition of glucose. This is basic for quantitative detection of glucose.

\section{Effect of the insert layer of $\mathrm{SiO}_{2} \mathrm{NSs}$}

Fig. 5a displays the photocurrent responses at the $\mathrm{ITO} / \mathrm{PbS}$ electrode and ITO/PbS/AuNPs electrode. The ITO/PbS photoelectrode exhibited a good photocurrent response in the presence of oxygen in the system. The ITO/PbS/AuNPs electrode was prepared by direct assembly of AuNPs on the surface of $\mathrm{PbS}$ layer. Comparison with the ITO/PbS electrode, the photocurrent at the ITO/PbS/AuNPs electrode reduced markedly. Especially, the base current of the photoelectrode was very high due to the excellent conductivity of gold, which was unfavorable for quantitative detection. Therefore, we tried to insert $\mathrm{SiO}_{2} \mathrm{NSs}$ between the PbS layer and AuNPs. As increasing the addition concentration of $\mathrm{SiO}_{2}$, the base current of the photoelectrode was reducing, but the photocurrent intensity was little change (Fig. S3 $\dagger$ ). When the addition concentration of $\mathrm{SiO}_{2}$ was $0.22 \mathrm{~mol} \mathrm{~L}^{-1}$, the base current of the $\mathrm{ITO} / \mathrm{PbS} / \mathrm{SiO}_{2} / \mathrm{AuNPs}$ electrode was similar to that of the ITO/PbS electrode. Considering that too thick $\mathrm{SiO}_{2}$ layer may hinder the irradiation of LED lamp and diffusion of oxygen, $0.22 \mathrm{~mol} \mathrm{~L}^{-1}$ was selected as the optimal concentration of $\mathrm{SiO}_{2}$ in the next experiments. As shown in Fig. $5 \mathrm{~b}$, the photocurrent of $\mathrm{ITO} / \mathrm{PbS} / \mathrm{SiO}_{2}$ electrode was only reduced by about $30 \%$ compared with that of $\mathrm{ITO} / \mathrm{PbS}$ photoelectrode. Furthermore, the photocurrent response of 

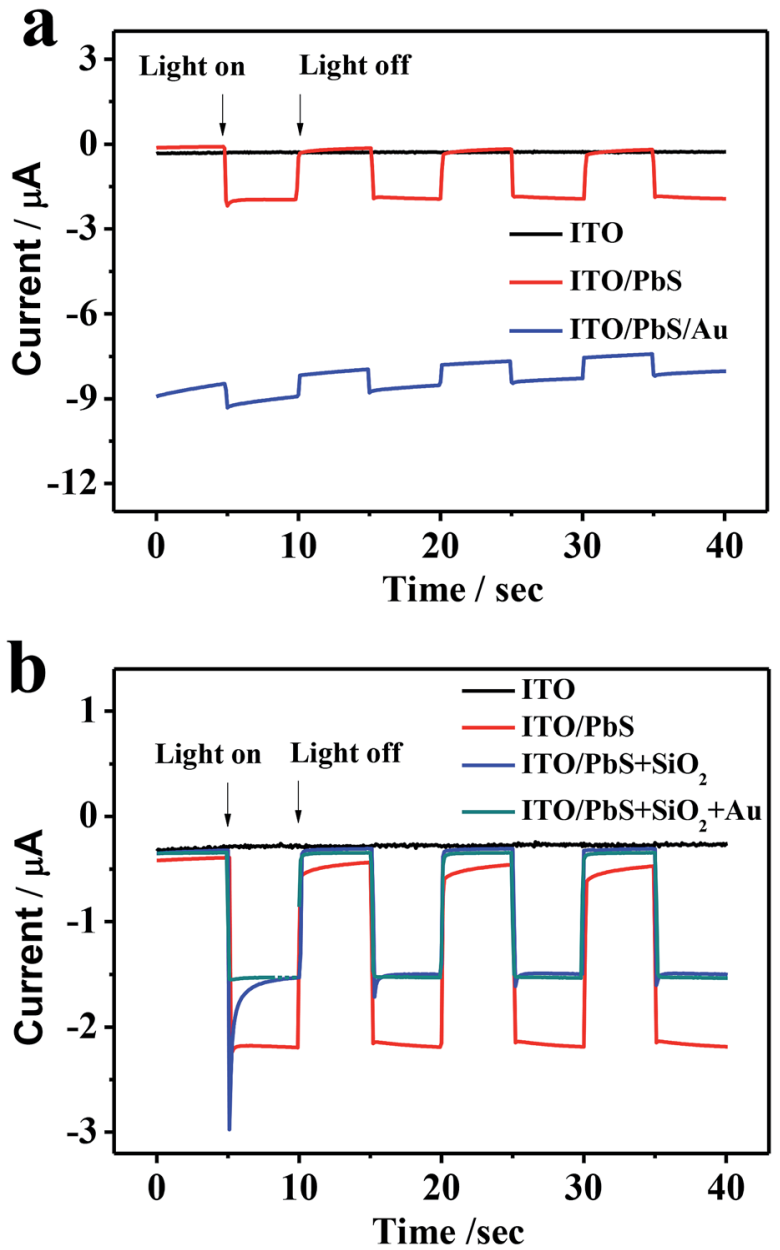

Fig. 5 (a) Photocurrent responses of the ITO, ITO/PbS and ITO/PbS/ AuNPs electrodes; (b) photocurrent responses of the ITO, ITO/PbS, ITO/PbS/SiO 2 , and $1 \mathrm{TO} / \mathrm{PbS} / \mathrm{SiO}_{2} /$ AuNPs electrodes. Experimental condition: $0.1 \mathrm{M}$ Tris $-\mathrm{HCl}$ buffer $(\mathrm{pH}$ 7.4) with oxygen, applied potential of $-0.2 \mathrm{~V}$.

ITO/PbS/SiO $/$ AuNPs electrode was similar to that of the ITO/ $\mathrm{PbS} / \mathrm{SiO}_{2}$ electrode, attributing to low conductivity of $\mathrm{SiO}_{2} \mathrm{NSs}^{36}$ These results demonstrated that the insert layer of $\mathrm{SiO}_{2} \mathrm{NSs}$ between PbS QDs and AuNPs could not only maintain most of PEC activity but also efficiently reduce base current.

\section{Optimization of experimental conditions}

The cathodic photocurrent intensity was dependent on the $\mathrm{pH}$ of buffer solution. As shown in Fig. S4a, $\uparrow$ the photocurrent response was low when the $\mathrm{pH}$ value was below 6.2. The photocurrent intensity increased gradually with the increasing of $\mathrm{pH}$ value over 7.4. Considering physiological condition $\mathrm{pH}$ value, $\mathrm{pH}=7.4$ Tris- $\mathrm{HCl}$ buffer solution was selected as the supporting electrolyte.

The applied potential is another significant factor to the photocurrent response. Fig. S4b $\dagger$ shows that the cathodic photocurrent response increased with negative shift of the applied potential from 0 to $-0.2 \mathrm{~V}$, and then reached a plateau.
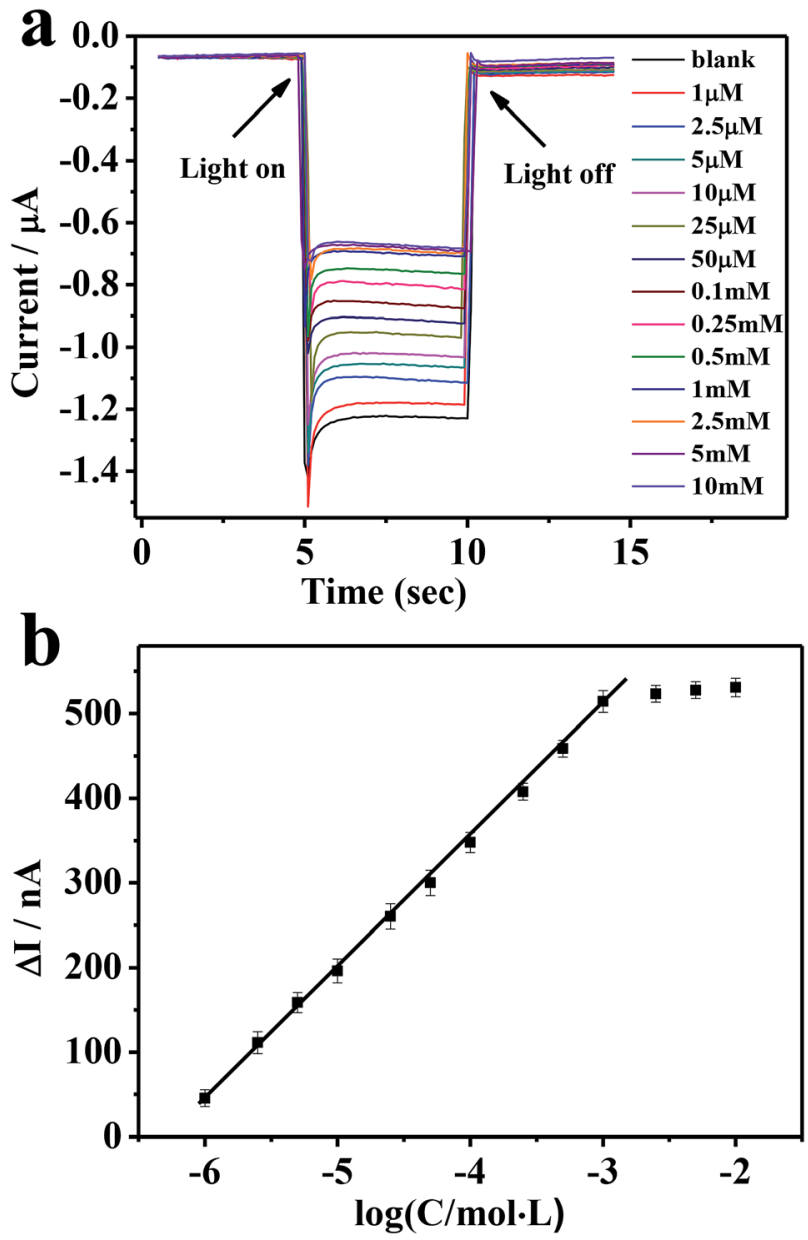

Fig. 6 (a) Photocurrent responses of the electrode corresponding to different glucose concentrations. (b) A plot of photocurrent decrease $(\Delta /)$ of the ITO/PbS/SiO $2 /$ AuNPs electrode vs. log $C$ glucose.

Therefore, an optimal potential of $-0.2 \mathrm{~V}$ was employed in the next PEC measurements.

\section{PEC detection of glucose}

We then applied the developed ITO/PbS/SiO $/$ /AuNPs photoelectrode for glucose determination. Fig. 6a illustrates the photocurrent responses in the presence of variable glucose concentrations at a bias potential of $-0.2 \mathrm{~V}$. The photocurrent intensity decreased steadily with the increasing of glucose concentration, reaching a saturation level of $1 \mathrm{mM}$. The negative correlation between the observed cathodic photocurrent and glucose concentration is due to the competition between the photocathode and the mimic enzyme of AuNPs for dissolved oxygen..$^{37}$ As mentioned above, when the immobilized electrode is exposed to a solution containing glucose, AuNPs can effectively catalyze the conversion of glucose into gluconic acid and hydrogen peroxide consuming dissolved oxygen, thereby inhibiting photo-induced electron transfer and inhibiting the cathodic photocurrent. Fig. 6b depicts the corresponding exported calibration curve. There is a good linear relationship between the change of optical current and the opposite value of 
Table 1 Comparison of linear range and limit of detection of various PEC sensors for detection of glucose

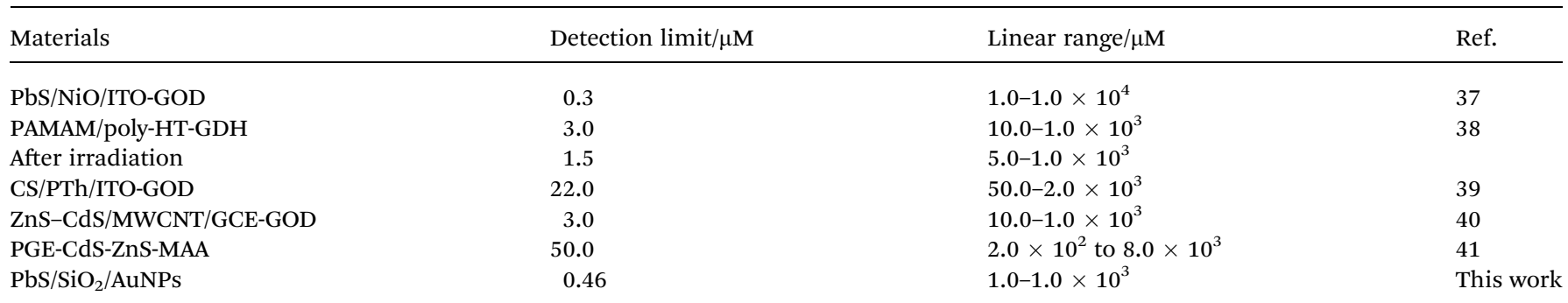

glucose concentration $(R=0.9988)$. The detection range is from $1.0 \times 10^{-6}$ to $1.0 \times 10^{-3} \mathrm{M}$, and the detection limit is $4.6 \times$ $10^{-7} \mathrm{M}$. As shown in Table 1, the linear range and detection limit of glucose detected by this sensor are better than the previous glucose PEC enzyme sensors. By comparison with GOD-based PEC biosensor, ${ }^{37}$ the linear lower limit was similar but the linear upper limit was obviously smaller. This was attributed to the lower catalytic capacity of AuNPs.

\section{Selectivity, reproducibility and stability of the PEC sensor}

The selectivity of the proposed sensor was then evaluated, as shown in Fig. 7. Common interfering species, such as ascorbic acid (AA), uric acid (UA), cysteine (L-cys), lactose, maltose, and sucrose, were investigated. Although the normal physiological glucose level in human blood is 3-8 mM, nearly 30 times higher than those of many of the interfering species, the interference experiment used glucose at the same concentration as the interfering species $(0.1 \mathrm{mM})$. Clearly, none of these species had any influence except for the glucose, revealing the excellent antiinterference ability against the reductive co-exists in biological samples and hence have great potential in PEC biosensing. The reproducibility of this system was assessed by an inter-assay relative standard deviation (RSD) through testing $1.0 \times$ $10^{-4} \mathrm{mM}$ samples with five electrodes, and a RSD of $6.8 \%$ was calculated. An intra-assay relative standard deviation (RSD)

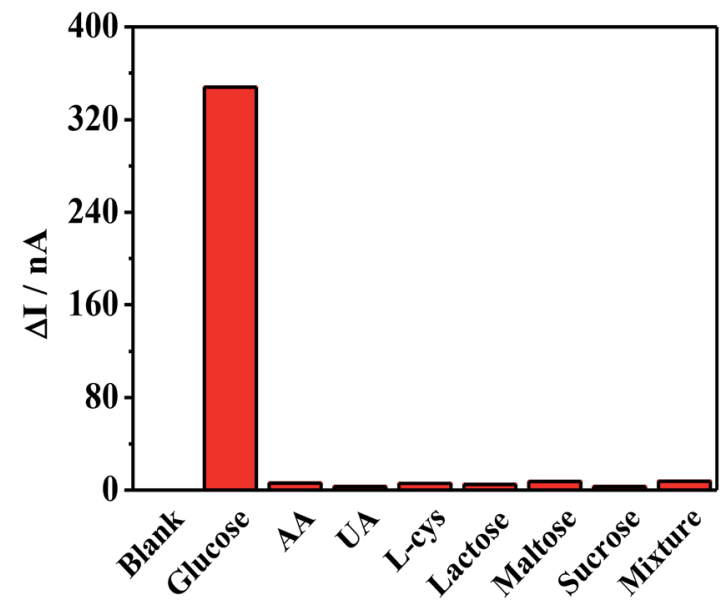

Fig. 7 Effect of different substances $\left(1.0 \times 10^{-4} \mathrm{M}\right)$, blank, glucose, ascorbic acid (AA), uric acid (UA), cysteine (L-cys), lactose, maltose, sucrose, mixture groups on the photocurrent intensity of the ITO/PbS/ $\mathrm{SiO}_{2} /$ AuNPs electrode. through testing blank solution six times, and a RSD of $1.2 \%$ was calculated. Both of them suggested good reproducibility of the photoelectrode. Fig. S5a $\uparrow$ shows the corresponding stability of the photocurrent of the electrode after 60 times of excitation, with no obvious change in cathodic photocurrent response. And the storage stability of the ITO/PbS/SiO${ }_{2} / \mathrm{AuNPs}$ electrode is shown in Fig. S5b. $\dagger$ After four weeks, the current value was $92 \%$ of the initial value, exhibiting good stability.

\section{Human serum sample measurements}

To evaluate the practicability of this glucose sensor, the asprepared ITO/PbS/SiO $/$ /AuNPs photoelectrode was also employed to determine glucose concentration in human serum samples. These human serum samples were diluted 100 times before detection and standard glucose solutions were added to the samples for recovery test. The results presented in Table S1 $\uparrow$ showed that the recoveries for the human serum samples were satisfactory. Therefore, it can be stated that the developed glucose sensor is promising for the practical use.

\section{Conclusions}

In summary, a nanozyme-based PEC glucose sensor using ternary layers of $\mathrm{PbS} / \mathrm{SiO}_{2} / \mathrm{AuNPs}$ was constructed successfully. The TGA-capped PbS quantum dots was PEC active for oxygen. The insert layer of $\mathrm{SiO}_{2}$ nanospheres efficiently reduced base current due to its low electroconductivity. The small AuNPs, a mimic enzyme of GOD, could catalytically oxidize glucose to generate gluconic acid and hydrogen peroxide in the presence of oxygen, which consumed oxygen in situ at electrode surface. This proposed sensor exhibited excellent analytical performance in terms of high sensitivity, good selectivity, and rapid response. In comparison with natural enzyme, nanozymes possess the advantages of high stability, easy preparation, and low cost. It is expected to offer great potential for design and development of nanozyme-based PEC sensors.

\section{Conflicts of interest}

There are no conflicts to declare.

\section{Acknowledgements}

This work was financially supported by the National Natural Science Foundation of China (No. 21475092) and the Priority 
Academic Program Development of Jiangsu Higher Education Institutions.

\section{Notes and references}

1 H. C. Wang and A. R. Lee, J. Food Drug Anal., 2015, 23, 191200.

2 A. L. Galant, R. C. Kaufman and J. D. Wilson, Food Chem., 2015, 188, 149-160.

3 Y. Lin, F. Lu, Y. Tu and Z. Ren, Nano Lett., 2004, 4, 191-195.

$4 \mathrm{X}$. Yunsheng, Y. Jingjing, T. Kanghui, W. Jiajing and Y. Guang, Anal. Chem., 2013, 85, 6241-6247.

5 J. Mu, Y. He and Y. Wang, Talanta, 2016, 148, 22-28.

6 X. Zhang, X. Bi, W. Di and W. Qin, Sens. Actuators, B, 2016, 231, 714-722.

7 Y. Li, Y. Y. Song, C. Yang and X. H. Xia, Electrochem. Commun., 2007, 9, 981-988.

8 Y. G. Zhou, S. Yang, Q. Y. Qian and X. H. Xia, Electrochem. Commun., 2009, 11, 216-219.

9 X. Zhong, R. Yuan and Y. Q. Chai, Sens. Actuators, B, 2012, 162, 334-340.

10 C. D. A. Marquette and L. J. Blum, Biosens. Bioelectron., 2004, 19, 433-439.

11 S. Aurélie A-M, D. Bastien, L. C. J. Blum, A. P. Girard-Egrot and C. A. Marquette, Anal. Chem., 2010, 82, 2401.

12 X. Yi, W. Dong, X. Zhang, J. Xie and Y. Huang, Anal. Bioanal. Chem., 2016, 408, 1-8.

13 C. L. Haynes, C. R. Yonzon, X. Zhang and R. P. V. Duyne, J. Raman Spectrosc., 2005, 36, 471-484.

14 Z. S. Wu, G. Z. Zhou, J. H. Jiang, G. L. Shen and R. Q. Yu, Talanta, 2006, 70, 533-539.

15 I. Al-Ogaidi, H. Gou, A. K. Al-Kazaz, Z. P. Aguilar, A. K. Melconian, P. Zheng and N. Wu, Anal. Chim. Acta, 2014, 811, 76-80.

16 J. Lihua, S. Li, G. Shaojun, F. Youxing, W. Dan, W. Li, Y. Jianyuan and D. Shaojun, Biosens. Bioelectron., 2011, 26, 1965-1969.

17 L. Yu, Z. Na, Q. Fei, T. Wen, F. G. Zhong, N. B. Li and Q. L. Hong, Spectrochim. Acta, Part A, 2014, 118, 315-320.

18 S. Xiaoyue, C. Lujing, M. Juanjuan, Q. Zhaosheng, C. Jianrong and F. Hui, Analyst, 2014, 139, 2322-2325.

19 X. Zhang, X. Fang, B. Zhao, J. Xin, Y. Yao, D. Wu, Z. Gao and J. Kai, Electrochim. Acta, 2014, 133, 615-622.

20 M. Zheng, C. Yan, X. Li, S. Liu and Z. Tang, J. Electroanal. Chem., 2011, 656, 167-173.
21 J. Zhang, L. Tu, S. Zhao, G. Liu, Y. Wang, Y. Wang and Z. Yue, Biosens. Bioelectron., 2015, 67, 296-302.

22 J. Tang, Y. Wang, J. Li, P. Da, J. Geng and G. Zheng, J. Mater. Chem. A, 2014, 2, 6153-6157.

23 L. Youhui, R. Jinsong and Q. Xiaogang, Acc. Chem. Res., 2014, 47, 1097-1105.

24 C. L. Clark Jr and C. Lyons, Ann. N. Y. Acad. Sci., 2010, 102, 29-45.

25 Y. Wang, W. Wei, X. Liu and X. Zeng, Mater. Sci. Eng., C, 2009, 29, 50-54.

26 H. Sabahudin, L. Yali, K. B. Male and J. H. T. Luong, Anal. Chem., 2004, 76, 1083-1088.

27 J. Yun, L. Baoxin and C. Rui, Chem. Commun., 2010, 46, 8017-8019.

28 M. Comotti, C. D. Pina, R. Matarrese and M. Rossi, Angew. Chem., Int. Ed., 2004, 76, 1083-1088.

29 P. Beltrame, M. Comotti, C. Della Pina and M. Rossi, Appl. Catal., A, 2006, 297, 1-7.

30 S. S. Marukhyan and V. K. Gasparyan, Spectrochim. Acta, Part A, 2017, 173, 34-38.

31 Z. Dongdong, L. Weijie, L. Jiang, L. Huajie, M. Hongwei, H. Qing and F. Chunhai, Analyst, 2012, 137, 4435.

32 Y. Yu, K. Zhang and S. Sun, Appl. Surf. Sci., 2012, 258, 71817187.

33 A. Qileng, C. Yue, W. Jie, H. Lei, W. Liu, S. Zhang and Y. Liu, Sens. Actuators, B, 2017, 254, 727-735.

34 T. Cai, G. Yan, J. Yan, W. Ying and J. Di, RSC Adv., 2017, 7, 29122-29128.

35 T. Kundu and D. Misra, Electrochem. Solid-State Lett., 2005, 8, G35.

36 C. Surbhi, U. Sumant, K. Pushpendra, S. Nirupama, R. S. Vibha, S. Rohit and D. Sahab, Int. J. Hydrogen Energy, 2012, 37, 18713-18730.

37 W. X. Dai, L. Zhang, W. W. Zhao, X. D. Yu, J. J. Xu and H. Y. Chen, Anal. Chem., 2017, 89, 8070-8078.

38 D. G. Dilgin and H. İ. Gökçel, Anal. Methods, 2015, 7, 990999.

39 C. Zhao, Z. Zhang, Y. Zhao and J. Yu, Chin. J. Chem., 2012, 30, 1851-1856.

40 Ö. Sağlam and Y. Dilgin, Electroanalysis, 2017, 29, 13681376.

41 B. Ertek, C. Akgül and Y. Dilgin, RSC Adv., 2016, 6, 2005820066. 